\title{
Isolation, Characterization, and Substrate Properties of the External Limiting Membrane From the Avian Embryonic Optic Tectum
}

\author{
S. Kröger and L. Niehörster \\ Abteilung Biochemic, Max-Planck-Institut für Entwicklungsbiologie, Tübingen, Federal Republic of Germany
}

The external limiting membrane of the avian embryonic optic tectum is isolated by mechanically separating the neuronal mesencephalon from the overlying mesenchymal tissue. The preparation consists of a basal lamina which is covered on its neural side by endfeet of neuroepithelial cells and has attached to it on its meningeal side a collageneous stroma, containing blood vessels. The external limiting membrane can be flat-mounted on a piece of nitrocellulose filter as mechanical support. It covers an area between 0.3 and $1 \mathrm{~cm}^{2}$, depending on the age of the donor embryo. The endfeet can be removed together with all cellular components of the meninges by treatment with $2 \%$ Triton-X-100 or with distilled water. The basal lamina itself is approximately $80 \mathrm{~nm}$ thick and consists of two laminae rarae and a central lamina densa. Immunohistochemical staining reveals that the basal lamina in the embryo, after isolation and after detergent extraction of the isolated preparation, contains type IV collagen, nidogen, laminin, and low density heparan sulfate proteoglycan as do other basement membranes. Antibodies against the neural cell adhesion molecule (N-CAM), chondroitin sulfate proteoglycan, and fibronectin fail to stain the external limiting membrane, but these proteins were clearly identified in the blood vessel-containing meninges or in the optic tectum.

The flat-mounted external limiting membrane preparation was used as substrate to culture several different neural tissues of central and peripheral origin. Explants of neural crest cells, dorsal root ganglia, and sympathetic ganglia can be cultured on the external limiting membrane. All explants grow well on the basal lamina preparations whether the endfeet are attached or detergent-extracted prior to explantation; however, neurite outgrowth from sympathetic ganglia is reduced in the presence of the endfeet. Although the endfoot-lined external limiting membrane represents at least part of the immediate environment encountered by retinal axons as they invade the optic tectum and despite its excellent properties as a sub- strate for retinal axons in vitro, cues guiding the orientation of axons were not detected in the flatmounted preparation.

Key words: chick development, extracellular matrix, basement membrane, retinotectal projection, axonal growth, axonal guidance

\section{INTRODUCTION}

The functional properties of the nervous system critically depend on the establishment of accurate connections between spatially separated areas. These connections are generated during embryonic development when neurons send out axonal processes which grow along stereotyped pathways to reach their target sites. Adhesive as well as repulsive interactions between the growth cone at the axons' leading tip and its direct microenvironment are supposed to provide the necessary guiding influences for axonal growth (for review, see Dodd and Jessell, 1988). Very often growth cones navigating along precisely defined routes toward their final destination are found either in direct contact with (Nordlander and Singer, 1982; Roberts and Taylor, 1982; Easter et al., 1984; Scherer and Easter, 1984; Anderson and Tucker, 1988; Condic and Bentley, 1989) or at least in very close vicinity to basal laminae (Hinds and Hinds, 1974; Puelles and Bendala, 1978; Bodick and Levinthal, 1980; Rager, 1980; Holley, 1982; Nardi, 1983; Kuwada, 1986; Williams et al., 1986; Halfter et al., 1987; Letourneau et al., 1988; Halfter, 1988; Holt, 1989). Basal laminae are thin sheets of highly condensed extracellular matrix material localized at the basal side of epithelia and endothelia as well as on the surface of fat cells, muscle fibers and Schwann cells (for review see Timpl and Dzia-

Received February 13, 1990; revised May 11, 1990; accepted May 15, 1990.

S. Kröger is now at Department of Neurobiology, Stanford University School of Medicine, Stanford, CA 94305-5401. Address reprint requests there. 
dek, 1986). They have been postulated to play crucial roles in axonal growth and guidance in a number of different systems (for review see Sanes, 1989). It is well established that neuronal growth cones recognize and adhere well to a number of extracellular matrix proteins which are common constituents of basal laminae. However, only little is known about the contribution of basal laminae to the generation of most central nervous system pathways.

In order to search for general axon outgrowth-promoting properties and specific guidance information associated with a central nervous system basal lamina, we chose to study the properties of the external limiting membrane of the avian embryonic optic tectum. During normal development of the chick, the first retinal axons arrive at the anterio-ventral pole of the optic tectum at embryonic day 6 (E6) and subsequently invade more posterior parts (Goldberg, 1974). These retinal axons grow in the most superficial layer, called stratum opticum, subjacent to the external limiting membrane, a basement membrane that delineates the border between the neural tissue and the overlying mesenchymal meninges. Axons and basement membrane are only separated from each other by the outermost cytoplasmic processes (endfeet) of radially oriented neuroepithelial cells (Rager, 1980). The connectivity pattern between the eye and the optic tectum is topographically organized. The ventral retina is represented on the dorsal tectum and the dorsal retina on the ventral tectum. The temporal retina projects onto the anterior tectal half and the nasal retina onto the posterior half (DeLong and Coulombre, 1965). Accordingly, the majority of retinal axons invading the outermost stratum opticum of the optic tectum stop at the retinotopic position along their growth axis and penetrate the underlying stratum griseum et fibrosum superficiale, their layer of termination. This highly directed navigation of retinal growth cones on the tectal surface, the precision in finding their topographically localized target cells and the ability to correct their course in vivo (Nakamura and O'Leary, 1989) and after mechanical or biochemical perturbation (Thanos et al., 1984; Thanos and Bonhoeffer, 1986), imply positional labels along the path within their direct environment. Growth cones of retinal axons invading the optic tectum have been shown to grow underneath the external limiting membrane, directly apposed to the endfeet of neuroepithelial cells (Vanselow et al., 1989), and it is therefore conceivable that these endfeet contain the positional information needed for establishing the correct, topographically organized retinotectal projection. The importance of the endfeet is further supported by the observation that retinal growth cones arriving later in development grow superficial to already existing retinal axons, indicating a preference for the endfeet-containing, basement mem- brane-apposed part of the stratum opticum, compared to deeper areas of the same layer (Thanos and Bonhoeffer, 1983).

In this study we describe the mechanical isolation of the external limiting membrane from the avian embryonic optic tectum. This basement membrane preparation is initially covered on its entire neural side by a dense carpet of neuroepithelial cell endfeet and has attached to it parts of the meninges on the other, mesenchymal, side. Antibodies against several extracellular matrix molecules with prominent functions in developmental processes were used to characterize the basement membrane and its associated tissues. In addition, a method is described to flat-mount the external limiting membrane in an intact form. Neurons from the central and peripheral nervous system as well as neural crest cells can be effectively cultured on this flat-mounted basement membrane preparation. However, despite the excellent promotion of axonal elongation, the endfeet as well as the basal lamina itself do not appear to contain cues directing the orientation of retinal axons in vitro.

\section{MATERIALS AND METHODS}

\section{Isolation of the External Limiting Membrane}

The procedure for the mechanical preparation of the external limiting membrane is schematically shown in Figure 1. The mesencephalon was dissected out of the embryo and cut midsagittally. The epidermis and the meninges, consisting of collageneous stroma, blood vessels and mesenchymal cells were removed as far as possible (step 1 in Fig. 1). The remaining vascularized mesenchymal tissue was separated from the neural tectum by lifting the meninges up with a watchmaker's forceps and pulling it in ventral to dorsal direction (step 2 in Fig. 1). The tissues split, resulting in an external limiting membrane with the endfeet of the neuroepithelial cells attached to one side and the blood vessel-containing meninges on the other side as well as an optic tectum deprived of its basement membrane (step 3 in Fig. 1). For use as a cell culture substrate, the external limiting membrane was stretched and flat-mounted on a nitrocellulose filter (SM 13006; Sartorius, Göttingen, FRG; 0.45 $\mu \mathrm{m}$ pore size) in such a way that the meninges faces the filter and the endfeet-containing neural side of the basement membrane faces up (step 4 in Fig. 1). Better attachment of the basement membrane to the nitrocellulose is achieved by placing the nitrocellulose on a dry filter paper for about $30 \mathrm{sec}$. This procedure immobilizes the basement membrane, which can then be used as cell culture substrate. The endfeet as well as the cellular components of the meninges were removed by detergent treatment with $2 \%$ Triton X-100 in phosphate-buffered saline (PBS) or, alternatively, by hypoosmotic shock 

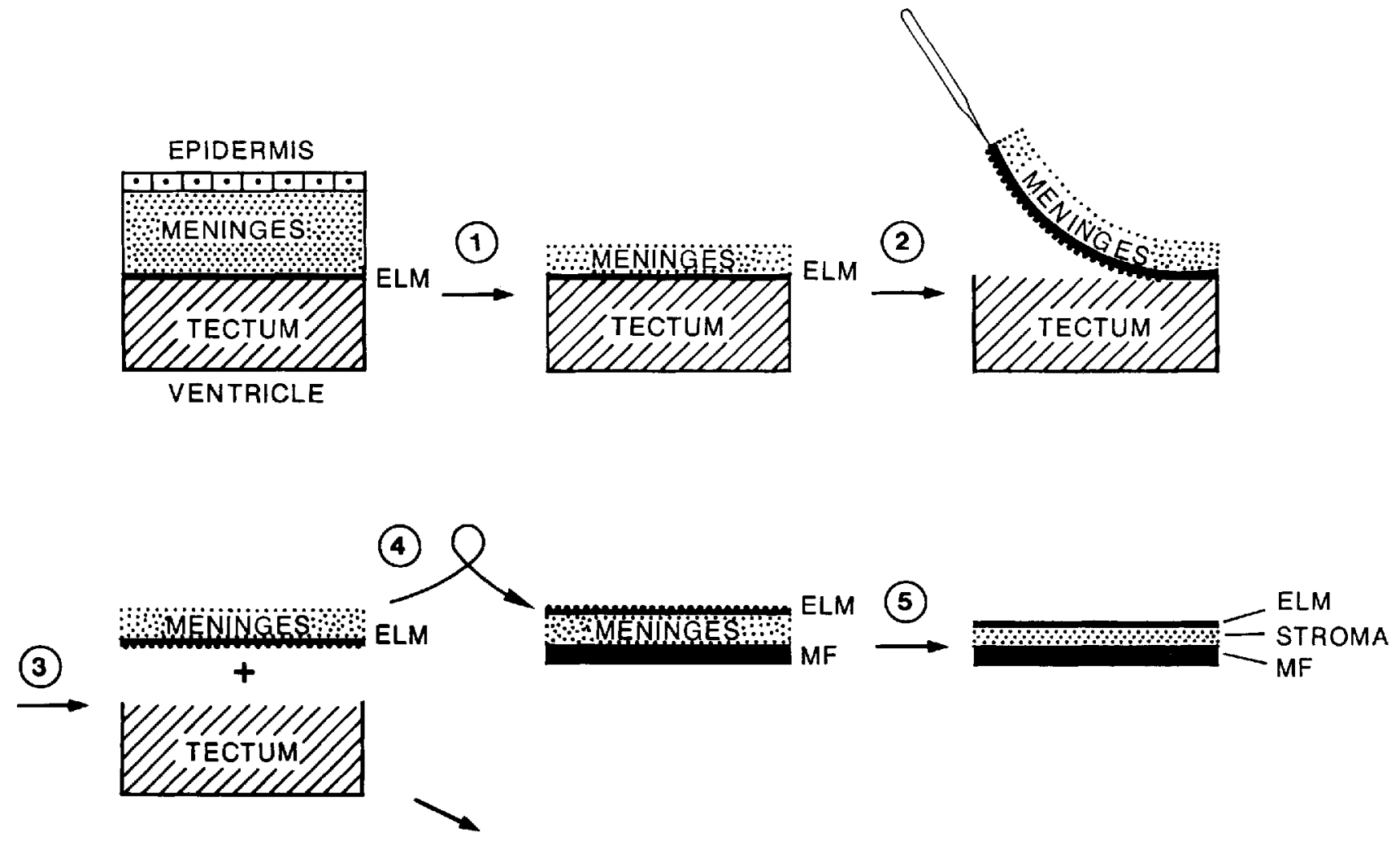

Fig. 1. Schematic representation of the isolation procedure for the external limiting membrane. The optic tectum is shown in cross section. For a detailed description of the different steps see Materials and Methods. ELM: external limiting membrane; MF: membrane filter.

with distilled water (step 5 in Fig. 1). After Triton-extraction the basement membrane preparation was extensively washed in PBS to remove the detergent. The basement membranes could be stored in culture medium for several days in the incubator without detectable change in morphology, antigenicity and substrate properties.

\section{Transmission Electron Microscopy}

Whole optic tecta as well as isolated external limiting membranes were fixed in $2.5 \%$ glutaraldehyde, $2 \%$

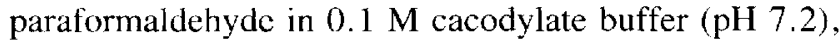
containing $0.1 \%$ ruthenium red, which selectively stains the basal laminae (Matsusaka, 1971; Kanwar and Farquhar, 1979). Specimens were postfixed in 1\% osmium tetroxide, dehydrated, and embedded in EPON (Roth, Karlsruhe, FRG). Ultrathin sections were cut, treated with uranyl acetate and lead citrate (Reynolds, 1963) and viewed in a Phillips CM 10 electron microscope.

\section{Immunohistochemistry}

A biochemical characterization of only the external limiting membrane is not possible since it cannot be isolated free of meningeal tissue, which itself contains extracellular stroma as well as basement membranes around the blood vessels. Therefore, we restricted the biochemical characterization to the localization of defined proteins with specific antibodies.

Cryostat sections of the external limiting membrane in whole heads or in isolated form--with or without Triton extraction-were prepared according to Halfter and Deiss (1986). Briefly, the tissue was fixed in $4 \%$ paraformaldehyde and $11 \%$ sucrose in $0.1 \mathrm{M}$ potassium phosphate buffer, $\mathrm{pH} 7.1$, and transferred into $25 \%$ sucrose after fixation. The tissue was then embedded in Tissue Tec O.C.T. compound (Miles, Naperville, IL.) and cut into $16 \mu \mathrm{m}$ thick sections with a microtome. Parallel sections were collected on glass slides previously coated with $0.5 \%$ gelatin, $0.05 \%$ chromalumn, airdricd overnight and stored at $-20^{\circ} \mathrm{C}$. After blocking with $0.2 \%$ bovine serum albumin (BSA) in PBS for $15 \mathrm{~min}$, sections were incubated with the primary antibody for 1 $\mathrm{hr}$, washed in PBS/BSA, and incubated with biotin-conjugated secondary antibody for $1 \mathrm{hr}$ (Biotin AffiPurc goat anti-rabbit or Biotin AffiPure goat anti-mouse, Dianova, Hamburg, FRG; 1:1,000 in PBS/BSA), washed again, and stained with fluorescein isothiocyanate (FITC)-conjugated streptavidin (Amersham, Braunschweig, FRG; 1 hr, 1:200 in PBS/BSA). After a final wash, the sections 
were embedded in PBS/glycerol (1:1; v:v) and viewed under a Zeiss Axioplan epifluorescence microscope. Corresponding parts of parallcl sections were selected and photographically documented. Elimination of the various primary antibodies showed the specificity of the immunostaining in all cases. Non-immune serum failed to label any structures in the cryostat sections.

The source and specificity of the rabbit polyclonal antisera directed against neural cell adhesion molccule (N-CAM), laminin, and fibronectin have been reported previously (Halfter et al., 1987). The monoclonal antibody against chondroitin sulfate proteoglycan (ChSPG) was commercially obtained as ascites fluid from Sigma (Munich, FRG; clone CS-56; see Avnur and Geiger, 1984) and used in a 1:2,000 dilution in PBS/BSA. Rabbit polyclonal antisera against the low-density form of heparan sulfate proteoglycan (HSPG), collagen type IV, and nidogen, isolated from the mouse Engelbreth-HolmSwarm (EHS) tumor, were a generous gift of R. Timpl (Max-Planck-Institut für Biochemie, München, FRG) and prepared as described previously (Dziadek et al., 1985a,b; Timpl, 1982).

\section{Cell Culture}

For explantation, only the epithelial (neural) side of the external limiting membrane was used. Dorsal root ganglia and sympathetic ganglia were dissected out of the lumbosacral region of E9 chick embryos and freed of nerve stumps and connective tissue. Explants from E6 retinac were prepared according to Halfter et al. (1983).

Neural crest cells were isolated as described by Newgreen et al. (1986). In short, blocks of tissue consisting of the last eight somites plus the neural anlage (neural tube and neural crest cells) were dissected out of the trunk region of E2.5 chick embryos. The neural anlage is easily separated from the adhering tissue after a 15 min incubation in $2 \mathrm{mg} / \mathrm{ml}$ Dispase II (Bochringer, Mannheim, FRG) in F 12-Medium without serum. After a 10 min recovery time in F 12 -Medium plus $10 \%$ FCS the neural anlagen were transferred into $1 \mathrm{ml}$ of the same medium containing $20 \mu \mathrm{g} / \mathrm{ml}$ Dil (D282; 1, $\mathrm{I}^{\prime}$, dioctadecyl-3,3,3',3',-tetramethylindocarbocyanine perchlorate; Molecular Probes Inc., Eugene, OR) and incubated at $37^{\circ} \mathrm{C}$ for $30 \mathrm{~min}$. After four washes in serum-containing medium, the neural anlage was positioned on the substrate and cultured as described for the other tissues. The labeled cells were visualized with a rhodamine filter combination and epifluorescence objectives.

All tissues were placed on the moist, flat-mounted external limiting membrane, before or after removal of the endfeet. After an attachment period of $45 \mathrm{~min}, \mathrm{~F}$ 12-Medium (Gibco, Eggenstein, FRG) containing 10\% fetal calf serum, $2 \%$ chicken serum, $0.4 \%$ methycellulose, glutamine ( $2 \mathrm{mM})$, penicillin, and streptomycin ( 10 units/ml) was carefully added. In the case of sensory and sympathetic ganglia explants, the medium was additionally supplemented with nerve growth factor (7S-NGF; $250 \mathrm{ng} / \mathrm{ml}$ final concentration; Bochringer, Mannheim, FRG). All cultures were maintained in $5 \% \mathrm{CO}_{2}$ at $37^{\circ} \mathrm{C}$ in a humidified incubator.

Since the external limiting membrane preparation is not transparent, direct visualization of the axons is not possible. Therefore, neurites emerging from the ganglia and the retinal explants were fixed after the incubation period and visualized with the Q211 antibody (Rösner et al., 1985; a generous gift of $\mathrm{S}$. Henke-Fahle). This monoclonal antibody binds to the ganglioside $\mathrm{GD}_{3}$ and brightly labels all postmitotic neurons (Rösner et al., 1988). Fixation and staining was performed as described for the cryostat sections.

The speed of axonal elongation was estimated by measuring axonal length after defined culture times with a calibrated ocular micrometer. The growth rate was calculated as the mean of at least three different experiments with four different explants each.

\section{RESULTS}

\section{Characterization of the External Limiting Membrane}

Mcchanical separation of the avian embryonic mesencephalon from its overlying mesenchymal tissue results in an external limiting membrane adhering to the meninges and neural tissue deprived of its basement membrane. External limiting membrane preparations can be obtained from embryos at all developmental stages beginning on E3 up to postnatal ages. The basement membranes are completely intact and cover an area between 0.3 at E4 and $1 \mathrm{~cm}^{2}$ at E12 and postnatal stages. Cell bodies and axons are not observed in preparations from E5 on, but at earlier stages, the neural tissue is too fragile for an accurate separation and therefore cells frequently remain attached to the basement membrane. After isolation, the external limiting membrane is entirely covered on its neural side by a dense carpet of neuroepithelial cell endfeet and has attached to it on the mesenchymal side a thick layer of collageneous stroma.

Transmission electron microscopy reveals the fine structure of the external limiting membrane and its associated tissues. The basement membrane is a continuous thin sheet with a rather amorphous appearance. It consists of collageneous stroma and a three-layered, approximately $80 \mathrm{~nm}$ wide basal lamina with two laminae rarae (clearly visible due to their preferential binding of ruthenium red) and a central, electron-dense lamina densa (Fig. 2a). Each of the laminae comprises approximately one-third of the total diameter of the basal lam- 
ina. Regular intervals of approximately $50 \mathrm{~nm}$ between ruthenium red clusters are observed (Fig. 2a).

The endfeet have a height of approximately $1 \mu \mathrm{m}$ at all embryonic stages, but their width increases with the age of the donor cmbryo, ranging between $1.5-2 \mu \mathrm{m}$ at E5 (Fig. 2a,b) and 5-7 $\mu \mathrm{m}$ at E16 (Fig. 2c). The increase in size shows a clear anterior to posterior gradient between $\mathrm{E} 6$ and E10 corresponding to the well-characterized developmental gradient in the mesencephalon (not shown, but see also Vanselow et al., 1989). We could not detect specialized contacts, such as desmosomes, between adjacent endfeet. No morphological difference can be observed between the external limiting membrane in the embryo and after isolation (compare Fig. $2 a$ and b). However, basement membranes from older embryos are considerably more compact and the regular intervals between the ruthenium red clusters are smaller, compared to those from younger embryos (compare Fig. $2 b$ and $c$ ).

Extraction of the basement membrane preparations with $2 \%$ Triton $\mathrm{X}-100$ removes the endfeet as well as all cellular components of the meninges (Fig. 2d). The ruthenium red clusters are also present in detergent-treated specimens, but their regular periodicity is lost (compare Fig. 2a with $2 \mathrm{~d}$ ). The three-layered structure of the in situ basement membranc is no longer visible (Fig. 2d). Treatment of the external limiting membrane with distilled water also removes the endfeet but largely preserves the ultrastructural characteristics of the in vivo basement membrane (Fig. 2e). In addition, the extraction with distilled water is not complete, since membranous material remains adherent to the basal lamina. Both extraction procedures result in a shrinkage of the mesenchymal stroma presumably because its cellular components are removed. Collagen fibrils in the meningeal stroma remain present after both treatments.

Antibodies directed against laminin, nidogen, collagen type IV, and low-density heparan sulfate proteoglycan are clearly detectable in the basement membrane (Fig. $3 \mathrm{~b}, \mathrm{c}, \mathrm{f}, \mathrm{g}$ ) but also appear in the moninges, either in the basement membranes around blood vessels or as small plaques located in the stroma. All four antibodies reveal an almost identical staining pattern. With the exception of anti-laminin antibodies, which at higher concentrations label the endfeet of the neuroepithelial cells in a punctate pattern (not shown), none of these antibodies shows a positive signal within the neural optic tectum (but all antibodics label the basement membrane-containing capillaries vascularizing the neural tissuc). Antibodies against laminin, nidogen, type IV collagen, and heparan sulfate proteoglycan also label the basement membrane after isolation and after extraction of the isolated basement membrane with Triton (not shown). In contrast, N-CAM immunoreactivity appears to be con- fined to the neural part of the optic tectum (Fig. 3d). The surface of the neuroepithelial cell endfeet and other cells of the tectum are stained. After isolation, anti-N-CAM staining of the external limiting membrane preparation is associated with the endfeet of the neuroepithelial cells in a similar pattern as has been described for the retinal basal lamina (Halfter et al., 1987). All N-CAM immunorcactivity is lost after detergent extraction of the isolated basement membrane (not shown). Fibronectin is weakly present in the basement membrane of the blood vessels penetrating the optic tectum from the overlying leptomeninges (arrows in Fig. 2e) but not in the external limiting membrane itself. Antibodies directed against chondroitin sulfate proteoglycan label extracellular material in the mesenchymal stroma dircctly apposed to the basal lamina, but the external limiting membrane itself remains unstained (Fig. 3h).

\section{Explant Cultures on the External Limiting Membrane}

The isolated external limiting membrane can be spread and flat-mounted on a nitrocellulose filter as mechanical support and used for culturing neural tissue from the central and peripheral nervous system. Basement membranes from all stages have the same substrate quality in regard of the rate of advance of neurites and the axon density. For reasons of convenience, E9 basement membranes were generally used. These preparations cover an arca of approximately $0.7 \mathrm{~cm}^{2}$. Neither explanted cells nor their neurites were ever observed to leave the basement membrane substratum.

Explantation of E2.5 neural tube, labeled with DiI, on the external limiting membrane results in a massive migration of neural crest cells from the dorsal aspect of the neural tube (Fig. 4a). They are not well spread but have a bi- or multipolar morphology lacking extensive lamellipodia. Instead, they have several thin processes (Fig. 4b,c). The cells do not show extensive cell-cell contacts and at the periphery of the explant they become markedly dispersed. The speed of migration varied from cell to cell, but somc cells were detected up to $1 \mathrm{~mm}$ away from the explant after $12 \mathrm{hr}$ in culture. Migration of neural crest cells is independent of whether the endfeet are present or extracted prior to explantation.

Dorsal root ganglia explanted on the external limiting membrane show vigorous extension of neurites (Fig. 5a). These neurites grow seemingly unfasciculated in a radial pattern, oriented symmetrically in all directions away from the explanted ganglion. Growth cones are detected at the tips of the processes (arrows in Fig. 5 b,c). Frequently, branching of the axons is observed. The speed of axonal elongation is $60 \pm 10 \mu \mathrm{m} / \mathrm{hr}$ (mean $\pm \mathrm{SD}, \mathrm{N}=14$ ), independent of the presence or absence of the neuroepithelial cell endfeet. The number of axons 

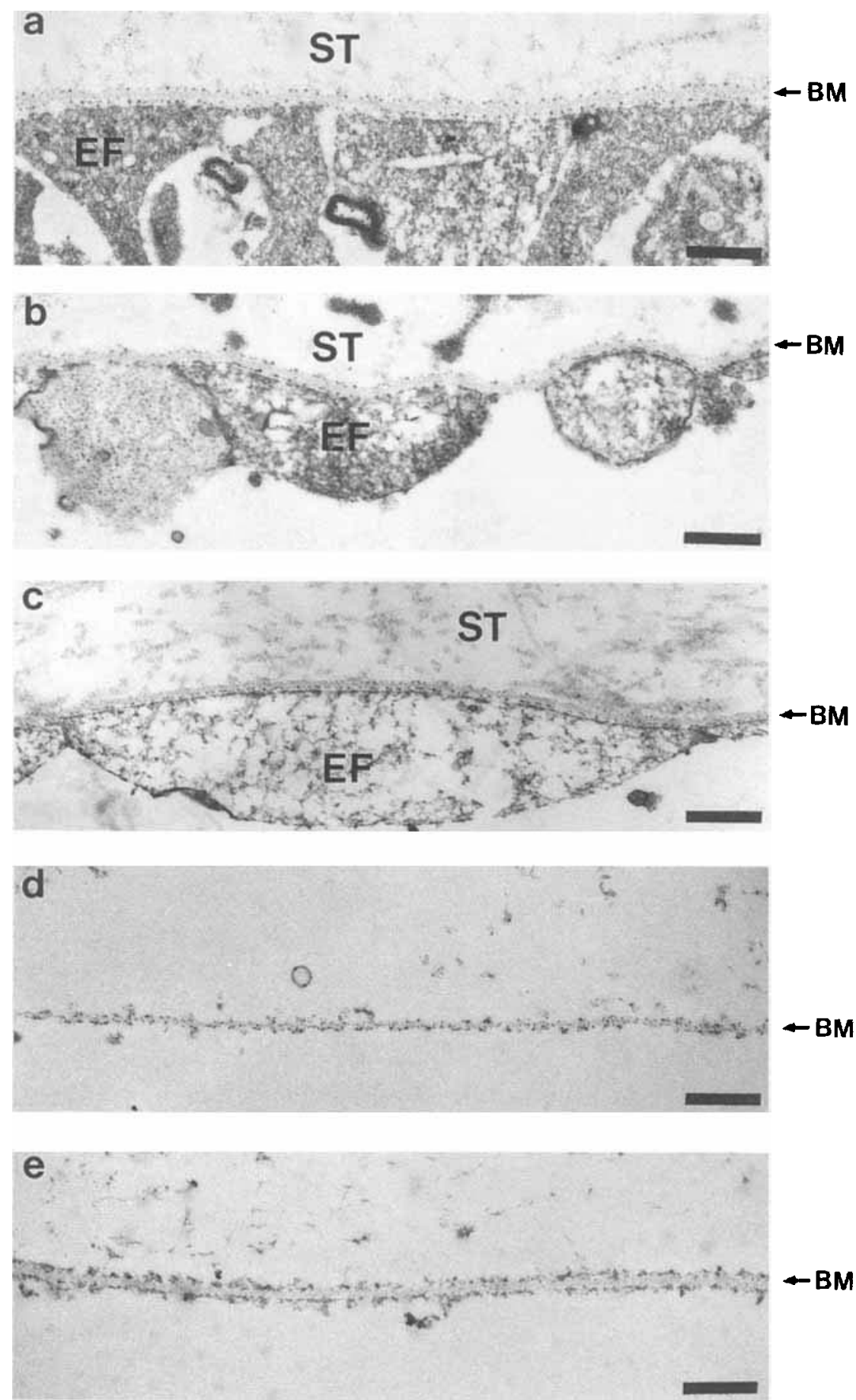

Fig. 2. Transmission electron-microscopic view of cross sections through the external limiting membrane (BM) in an intact E5 optic tectum (a), after mechanical isolation from an E5 (b) or E16 (c) embryo and after extraction of the isolated preparation with $2 \%$ Triton X-100 (d) or distilled water (e). Note the periodic ruthenium red binding to both laminae rarae in $a-c$.
The width of the ncuroepithelial cell endfeet (EF) increases between E5 and E16 (compare b with c). Triton X-100-extraction disorganizes the three-layered structure of the in situ basement membrane (compare $d$ and e). ST: meningeal stroma. Bar (a-e): $700 \mathrm{~nm}$. 

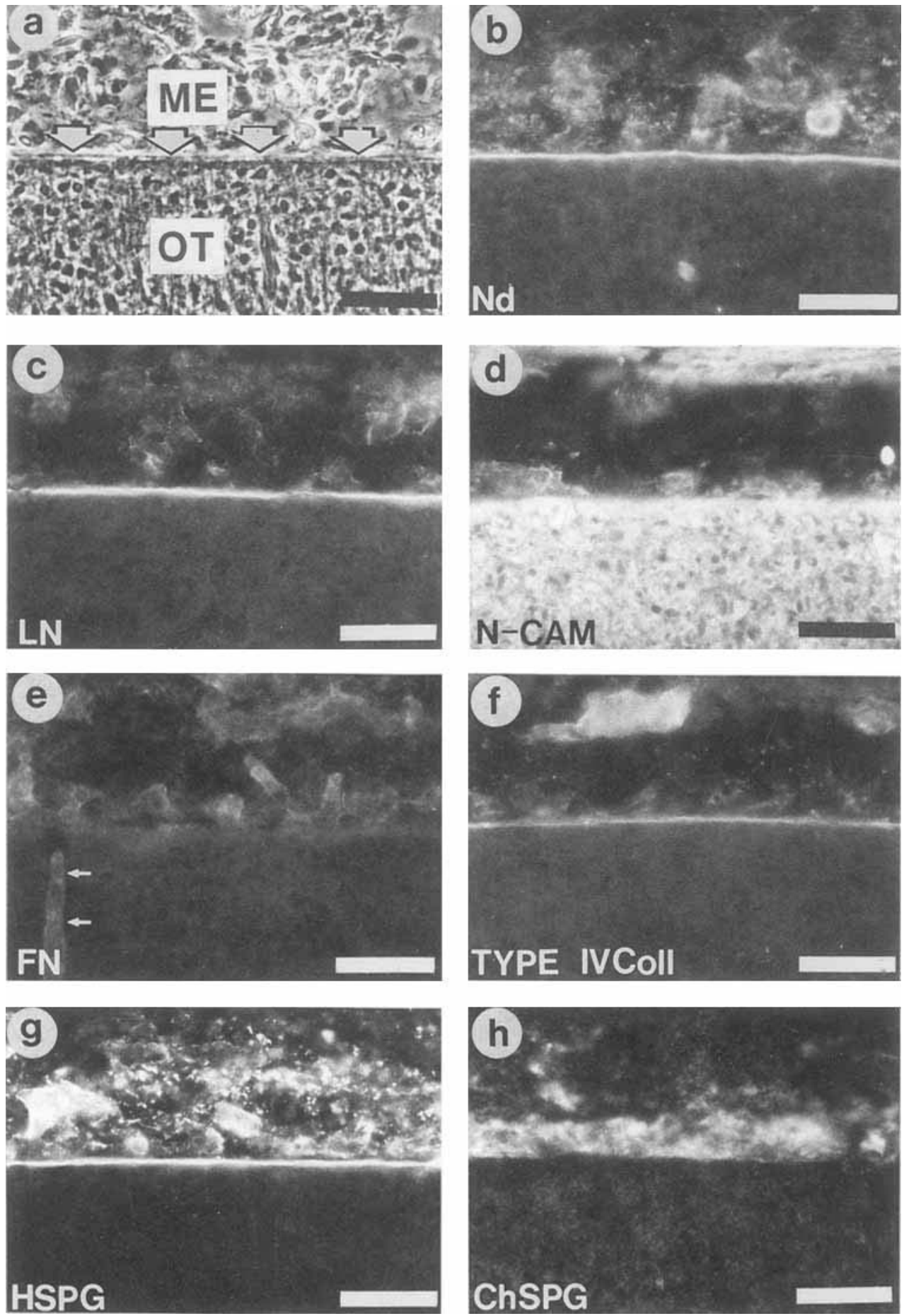

Fig. 3. Staining of the external limiting membrane in parallel sections of the mesencephalon with antibodies against nidogen (ND; b), laminin (LN; c), neural cell adhesion molecule $(\mathrm{N}$ CAM; d), fibronectin (FN; e), collagen type IV (type IV coll; f), low density heparan sulfate proteoglycan (HSPG; g), and chondroitin sulfate proteoglycan (ChSPG; h). A corresponding phase contrast picture is shown in a. The position of the external limiting membrane is indicated by the white arrows in a.

The basement membrane contains nidogen, laminin, type IV collagen, and hcparan sulfate proteoglycan. Fibroncctin and ChSPG are not detected in the external limiting membrane but are present in other structures of the optic tectum or the meninges. The arrows in c indicate a blood vessel penetrating the neural tissue from the overlying meninges. ME: meninges; OT: optic tectum. Bars $(\mathrm{a}-\mathrm{h})$ : $40 \mu \mathrm{m}$. 

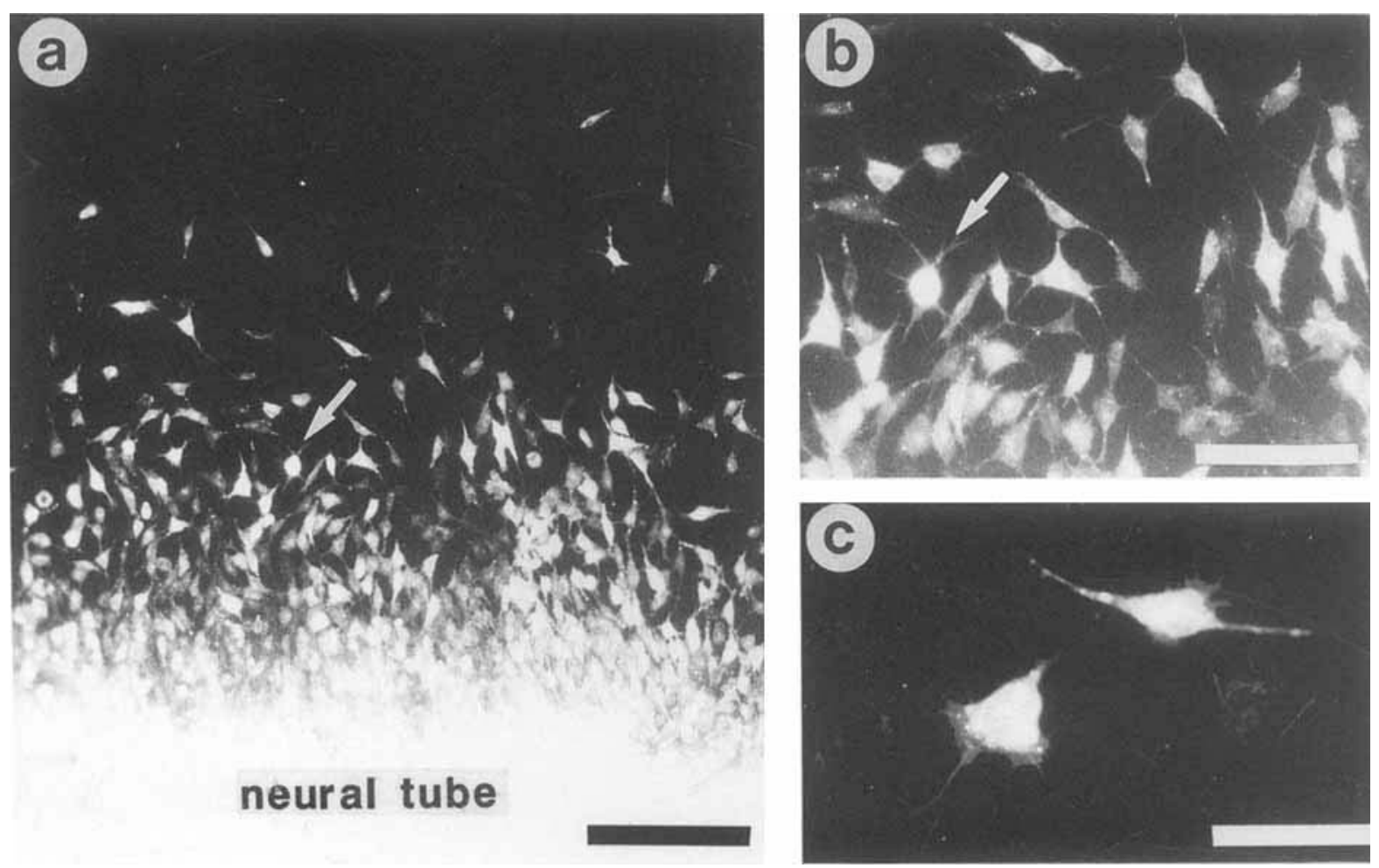

Fig. 4. Culture of neural crest cells on the external limiting membrane. The neural anlage (neural tube and neural crest) was labeled with Dil prior to explantation. After the $12 \mathrm{hr}$ culture period, the neural crest cells have migrated up to $1 \mathrm{~mm}$ away from the explant (a). There is only a minimal overlap of

leaving the ganglion, however, appears to be slightly reduced if the basement membrane is Triton-extracted prior to explantation (not shown).

Sympathetic ganglia explanted on the external limiting membrane also show a radially symmetric halo of neurite outgrowth (Fig. 6a). On Triton- or distilled water-extracted preparations, sympathetic axons have a strong tendency to form fascicles, indicating a preference for the surface of other axons compared to the substrate. The growth rate is $55 \pm 7 \mu \mathrm{m} / \mathrm{hr}$ (mean $\pm \mathrm{SD}, \mathrm{N}=12$ ) and thus comparable to that of dorsal root ganglia. Interestingly, the growth pattern is different on endfeetcontaining basement membranes. Sympathetic ganglia, when explanted on basement membrane preparations still covered by neuroepithelial cell endfeet, send out fine radially oriented axons which elongate at a rather slow speed of $8 \pm 3 \mu \mathrm{m} / \mathrm{hr}$ (mean $\pm \mathrm{SD}, \mathrm{N}=12$ ) (Fig. 6b). Outgrowth is still symmetric to all sides but considerably less fasciculated.

\section{Orientation of Retinal Axons on the External Limiting Membrane}

Since the endfeet-containing external limiting membrane preparation represents at least part of the di- the cells. $\mathbf{b}$ shows a higher magnification of a. The arrows in $\mathrm{a}$ and $\mathrm{b}$ indicate corresponding cells. $\mathrm{c}$ shows the detailed morphology of two typical neural crest cells. Note the thin filipodial processes. Calibration bars: a, $200 \mu \mathrm{m} ; \mathrm{b}, 100 \mu \mathrm{m}$, c, $50 \mu \mathrm{m}$.

rect in vivo environment of retinal axons invading the embryonic optic tectum, we looked for the presence of cues which could direct the orientation of retinal axons in vitro. For this purpose, stripes of retinal tissue from several defined positions were placed on the flat-mounted basement membrane in various orientations. Neurite outgrowth occurred with the same rate of advancement and axon density on basement membranes from all stages of embryonic development. This was true of preparations with and without endfeet. The rate of neurite extension was $75 \pm 5 \mu \mathrm{m} / \mathrm{hr}$ (mean $\pm \mathrm{SD}, \mathrm{N}=16$ ), which is identical to the growth rate observed in situ (Halfter and Deiss, 1986). As has been previously described for growth on other substrates like laminin, collagen or retinal basal lamina (Halfter et al., 1983, 1987), the majority of fibers grow out from the side of the explant stripe that had faced the optic nerve head or the optic fissure in the eye. Thus, outgrowth of retinal axons in vitro on the basement membrane resembles the growth pattern of the axons in the embryo. However, in no case is the orientation of the axons directed by the underlying substrate. Even when fibers are cultured on basement membrane preparations from E10 optic tectum, where the endfeet are arranged in parallel rows with anterior to 

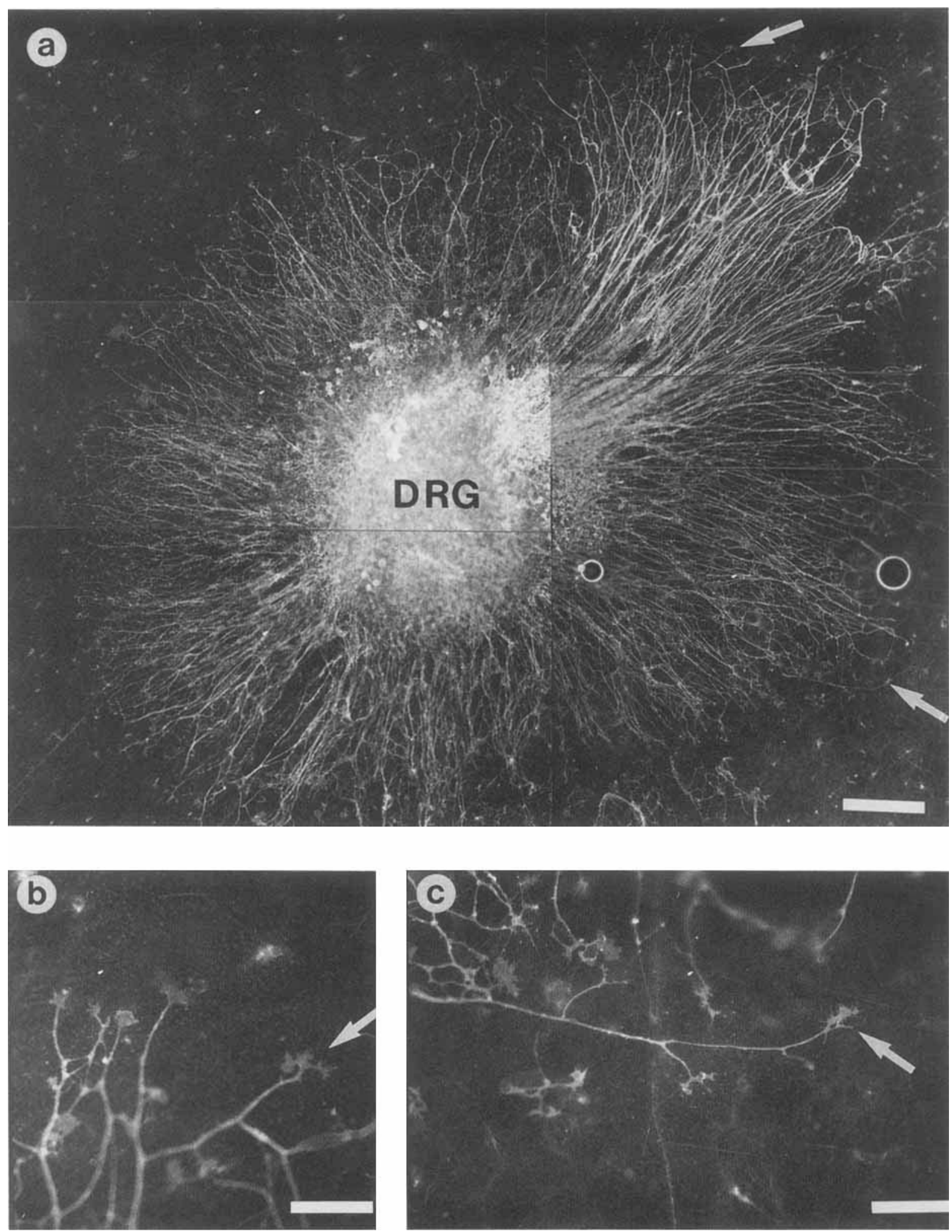

Fig. 5. A chick dorsal root ganglion (DRG) explanted on the external limiting membrane. Axonal outgrowth is radial and in fine fascicles. $\mathbf{b}$ and $\mathbf{c}$ show two examples of growth cones. The arrows in $b$ and $c$ correspond to the two arrows in a. Growth cones have the normal flattened morphology with one lamellipodium and several filopodia. Axons were fixed and visualized thereafter with the Q 211 monoclonal antibody as described in Materials and Methods. Note the frequent branching of the axons in b and c. Culture period: $24 \mathrm{hr}$. Bars: a, 200 $\mu \mathrm{m} ; \mathrm{b}, \mathrm{c}, 50 \mu \mathrm{m}$. 

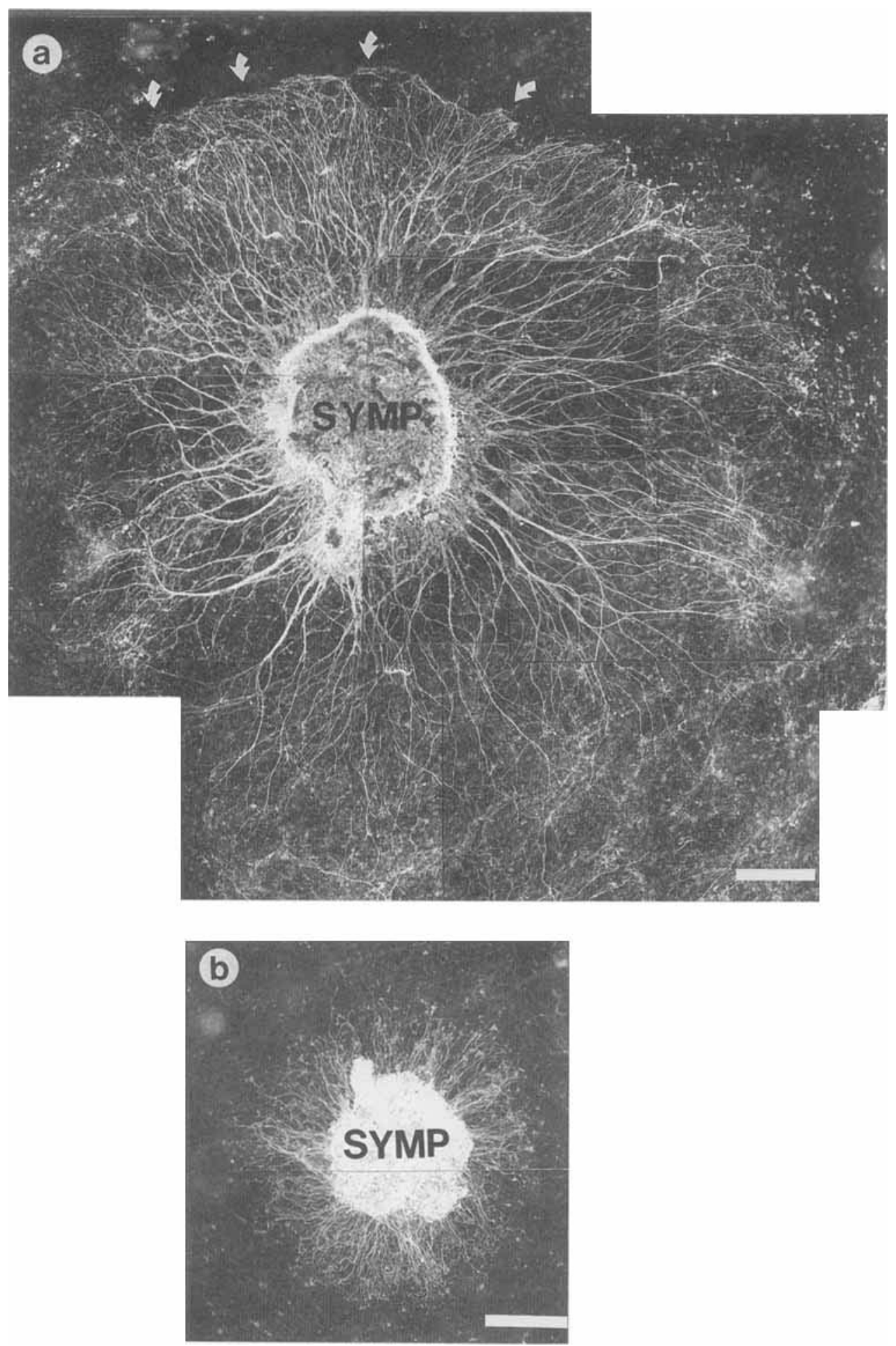

Fig. 6. A chick sympathetic ganglion (SYMP) explanted on the external limiting membrane before (b) and after (a) extraction with $2 \%$ Triton X-100. Note the rather fasciculated outgrowth on the extracted basement membrane in a and the fine and unfasciculated outgrowth on the non-extracted basement membrane in b. On both substrates, outgrowth is radially sym- metric on all sides of the explanted ganglion. Axonal growth is restricted to the confines of the basement membrane (indicated by the arrows in a). Axons were visualized by indirect immunofluorescence with the Q211 antibody. Culture period: $24 \mathrm{hr}$. Calibration bar (a,b): $200 \mu \mathrm{m}$. 


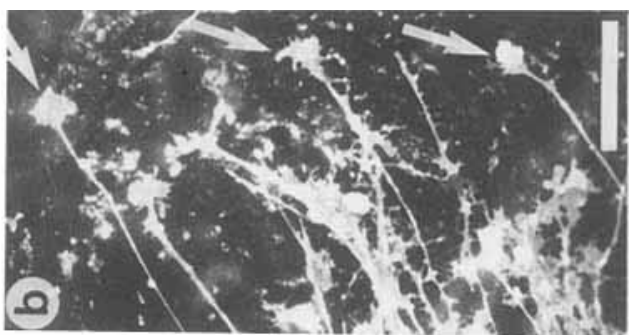

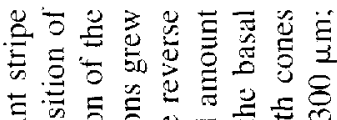

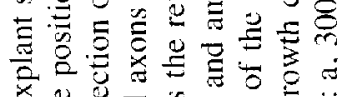

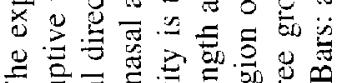

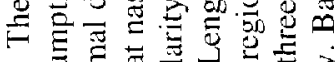

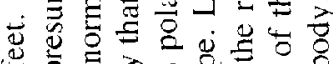

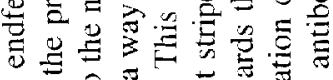

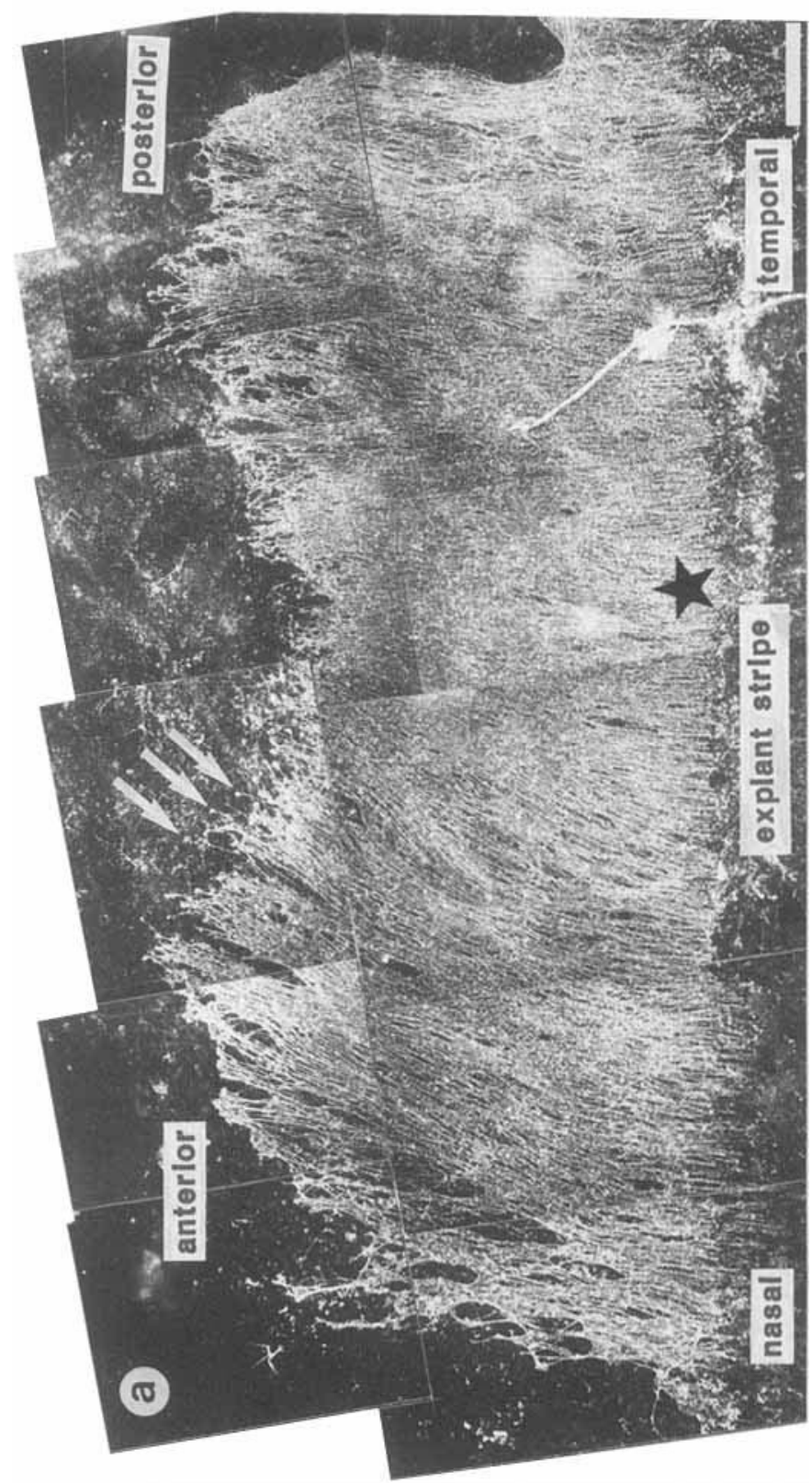

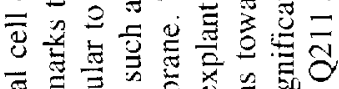

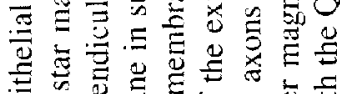

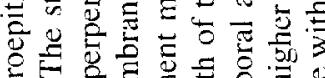

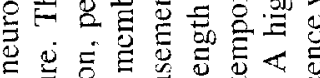

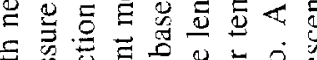

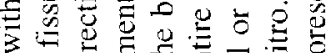

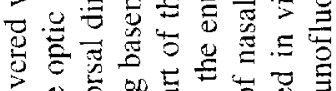

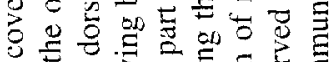

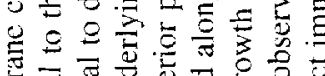

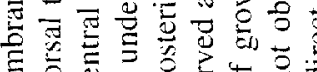

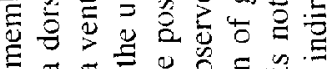

ग

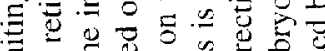

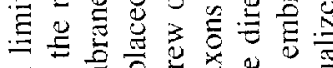

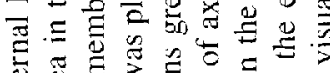

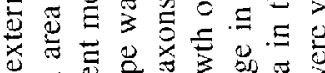

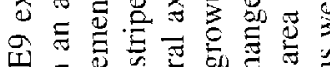

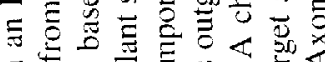

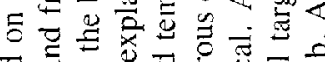

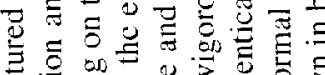

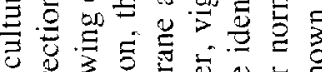

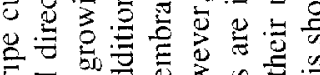

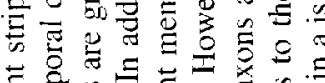

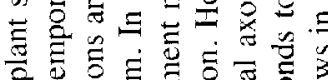

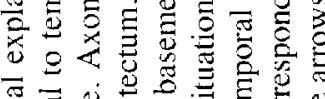

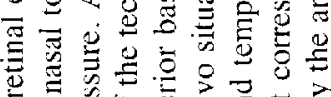

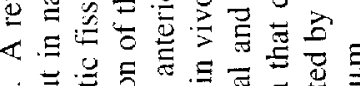

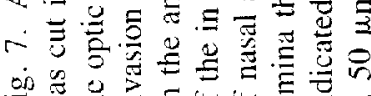

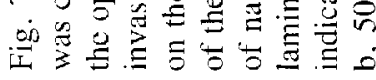


posterior orientation (Vanselow et al., 1989), axons are never influenced in their directionality. This behavior is illustrated in Figure 7, where an explant stripe from a region of the eye dorsal to the optic fissure, was cut in a nasal to temporal direction and placed on a basement membrane preparation in a way that favoured growth from ventral to dorsal, perpendicular to the in vivo direction. In addition, the topological orientation was reversed in vitro, i.e., nasal axons which normally project to the posterior tectal half were grown on the basement membrane part corresponding to the anterior tectum, and temporal axons were explanted in the posterior part of the basement membrane, an area which they never invade in vivo. An E9 basement membrane was taken, since this corresponds to the stage where the highest number of ingrowing retinal axons is observed in vivo (Rager, 1989). As shown in Figure 7a, despite excellent neurite outgrowth, no orientation of nasal or temporal axons in either an anterior or posterior direction (towards their appropriate topological target area) can be detected. In addition, the density of outgrowth as well as the rate of elongation appears to be identical for nasal and temporal axons even in this ectopic position. Growth cones from nasal or temporal retinal origin growing in vitro on the external limiting membrane have a size and morphology indistinguishable from retinal axons growing on the retinal basal lamina (Halfter et al., 1987); i.e., they are short and flattened with a diameter of approximately 10 $\mu \mathrm{m}$ and consist of several microspikes and large lamellipodia (Fig. 7b).

\section{DISCUSSION}

The external limiting membrane delineates the border between the neural optic tectum and the meningeal connective tissue. In this study we describe a procedure to isolate and flat-mount this basement membrane. In addition, we characterize components of this basement membrane and its substrate propertics.

Mechanical separation of the optic tectum from the overlying mesenchymal meninges cleaves the neural tissue in a reproducible way. The tissue separates just underneath the endfeet of the radially oriented neuroepithelial cells and, thus, yields meninges with the external limiting membrane attached and an optic tectum deprived of its basement membrane. Presumably, the cleavage occurs along the plane where most of the extracellular space is found and where the cells have the least mechanical stability. The same procedure can be applied to the meninges covering other parts of the central nervous system like spinal cord, cerebellum or forebrain (S. Kröger, unpublished observation). In any case, a basement membrane is obtained which is covered on its neural side by a dense carpet of neuroepithelial cell end- feet and has attached to it on the other (meningeal) side, blood vessel-containing mesenchymal stroma. It will be of interest to compare these different basement membrane preparations in respect of their substrate propertics.

The external limiting membrane has a morphology similar to that described for several other basement membranes from different sources (Kanwar and Farquhar, 1979; Scherer and Easter, 1984; Kuffler, 1986; Halfter et al., 1987; Anderson and Tucker, 1988; Halfter, 1988; Schittny et al., 1988). It consists of a three-layered basal lamina and associated collageneous stroma. In addition, the external limiting membrane in the embryo contains molecules characteristic of basement membranes like, laminin, nidogen, heparan sulfate proteoglycan, and collagen type IV. These molecules remain detectable after isolation and after detergent extraction of the isolated preparation. The localization of these proteins in the basement membrane and in stromal plaques resembles that in the corneal basement membrane (Schittny et al., 1988). Furthermore, a similar periodicity of ruthenium red binding to the laminae rarae has been described previously for the glomerular basement membrane (Kanwar and Farquhar, 1979).

The isolation procedure provides two kinds of tissue culture substrata, consisting of either a dense carpet of neuroepithelial cell endfeet on a basal lamina or a pure basal lamina. Both types of substrate have the same excellent outgrowth-promoting properties for axons from dorsal root ganglia and retinal explants. However, a difference in the pattern of neurite outgrowth between endfeet-containing and denuded basement membrane is observed in the case of sympathetic axons. Several possibilities might explain this behavior. For example, the endfeet might themselves be a poor substrate for sympathetic axons or mechanically block the access of the growth cones to the underlying basal lamina substrate. Alternatively, these endfeet might contain a component on their surface which actively reduces the speed of axonal elongation. Several experimental systems have revealed a negative regulation of cell migration and process elongation (for review see Patterson, 1988). The growth rate of sympathetic axons on a basal lamina preparation from the embryonic chick eye (Halfter et al., 1987) is equivalent on the endfeet-containing and on the extracted preparation ( $S$. Kröger, unpublished observation) suggesting that the endfeet on the tectal basement membrane might be responsible for the reduced growth rate.

The difference in the speed of elongation of sympathetic axons on the external limiting membrane is accompanied by a difference in the pattern of neurite outgrowth. Axons change from fasciculated to unfasciculated growth which might suggest that different sub- 
strate molecules are used when sympathetic axons grow on the endfeet and on the plain basal lamina. The external limiting membrane contains several molecules which have previously been shown to be a substrate for axons from the central and peripheral nervous system, like laminin (Rogers et al., 1983; Manthorpe et al., 1983; Adler et al., 1985), collagen (Halfter et al., 1983) or heparan sulfate proteoglycan (Hantaz-Ambroise et al., 1987; Dow et al., 1988). These molecules remain in the basement membrane even after Triton-extraction. It remains to be shown which of these molecules is used by the different axons when growing on the external limiting membrane preparation. In any case, the behavior of sympathetic axons is specific since neither retinal axons nor dorsal root axons or neural crest cells show any difference in the growth pattern on both types of basement membrane substrate.

The external limiting membrane is distinct from conventionally employed culture substrata because it is a 2-dimensional, in vivo assembled, multicomponent substrate of embryonic origin. This might explain the excellent outgrowth promoting properties of the basement membrane. The rate of axonal growth of retinal axons, for example, in vitro on the tectal external limiting membrane is identical to that found in situ in organ-cultured retinae (Halfter and Deiss, 1986). Sympathetic neurons cultured on the external limiting membrane without the endfeet extend axons at a rate of about $55 \mu \mathrm{m} / \mathrm{hr}$, which is approximately twice as fast as on a monolayer of astrocytes (Fallon, 1985). The growth rates of axons from sympathetic ganglia and retinal explants on the tectal basement membrane are similar to those obtained with the basal lamina preparation from the embryonic chick retina (Halfter et al., 1987; S Krögcr, unpublished observation). Since dorsal root ganglia, sympathetic neurons, and neural crest cells never encounter the tectal external limiting membrane in the embryo, it may be that the growth-promoting activity of the external limiting membrane is a general feature of basement membranes, mediated by molecules that are common basal lamina constituents.

The external limiting membrane does not contain fibronectin but is rich in laminin and type IV collagen. A similar composition has been described for a basal lamina isolated from the embryonic chick eye (Halfter et al., 1987). Correspondingly, the morphology of neural crest cells cultured on the external limiting membrane is comparable to the morphology of neural crest cells cultured on the basal lamina from the eye and differs considerably from neural crest cells cultured on fibronectin (Halfter et al., 1989). Our observation that neural crest cells can attach and migrate on the fibronectin-free external limiting membrane is in agreement with previous in vitro studies showing that laminin is as good as fibronectin in stimulating neural crest cell migration (Newgrecn, 1984).

Despite this excellent outgrowth-promoting activity, the neuroepithelial cell endfeet as well as the external limiting membrane do not seem to contain, at least in vitro, signals or cues that regulate the orientation of growing nerve fibers. Dorsal root ganglia and sympathetic ganglia form a radially symmetric halo of neurite outgrowth. Likewise, the direction of growth of retinal axons is not influenced by the underlying neuroepithelial cell endfeet, although these endfeet represent at least part of their direct environment when invading the optic tectum. A reduction of the growth ratc of retinal axons approaching their target, as has been shown in living Xenopus embryos (Harris et al., 1987), could not be detected for neurites growing on the external limiting membrane from the embryonic chick optic tectum. Instead, retinal axons in vitro grow with the same speed of about $75 \mu \mathrm{m} / \mathrm{hr}$ on both the retinal and tectal basal lamina (Halfter et al., 1987). Consistent with the absence of guidance cues, growth cones of retinal axons growing on the external limiting membrane remain simple and flattened in morphology and do not become elongated and complex as has been described in vivo at decision points in their pathway (Bovolenta and Mason, 1987; Holt, 1989). Furthermore, axons did not correct their direction of growth in vitro when growing at an eclopic position on the basement membrane in a way resembling their behavior in vivo (Thanos et al., 1984; Thanos and Bonhoeffer, 1986; Nakamura and O'Leary, 1989).

Several mechanisms have been implicated in regulating the direction of axonal growth. These include preformed extracellular channels (Singer et al., 1979; Silver and Sidman, 1980), diffusible or non-diffusible gradients (Bonhoeffer and Gierer, 1984), electrical activity or a combination of several mechanisms. Most of these mechanisms require an intact, three-dimensional environment, which is lost during the basement membrane preparation. This might explain why directed axonal growth is not observed on the external limiting membrane in vitro, although the isolation procedure is relatively gentle and does not require enzyme treatment. Alternatively, guiding mechanisms might be present in the basement membranc, but not detectable in our culture system. For example, if the guiding cues are not all or none but instcad are displayed as slight preferences, they might only be detected if axons are confronted with a direct choice between two possiblities. A corresponding approach has been applied to retinal axons and has provided evidence for a developmentally regulated repulsive component in the optic tectum (Walter et al., 1987a,b). This type of guiding information would have escaped detection in our basement membrane culture system. Another explanation for the absence of detectable guiding 
cues in the tectal external limiting membrane is possible and has been implicated by a recent study by Nakamura and O'Lcary (1989) on the development of the retinotectal projection in the chick embryo. These authors provide evidence that the retinotectal map shows an early lack of topographic accuracy since a considerable amount of temporal axons grow past their appropriate termination zone along the rostro-caudal axis of the optic tectum. This initial imprecision is corrected during later stages of development by remodeling. These findings suggest that at least a large proportion of temporal retinal axons initially do not respond to the hypothetical positional markers either because the axons are not competent to respond or because markers are not present in their immediate environment. Our results favor the latter possibility although we certainly cannot rule out the other.

Basement membranes have been isolated and used as a culture substrate from various tissues. These include the embryonic retina (Halfter et al., 1987), the pigment epithelium (Halfter, 1988) and the human amnion (Davis et al., 1987). They all have in common with the external limiting membrane excellent growth-promoting properties. We suppose that all basement membranes contain onc or several extracellular matrix molecules that generally promote the growth of axons. However, signals or biochemical gradients that regulate the direction of axonal growth seem not to be imprinted in these preparations.

\section{ACKNOWLEDGMENTS}

We would like to thank R. Timpl, S. Henke-Fahle, and $F$. Rathjen for generously providing antisera and Inge Zimmermann for the ultrathin sectioning and Regine Braun for the Epon embedding. We are especially indebted to U. Schwarz, in whose department this work was carried out. The manuscript has been critically read and improved by B.G. Wallace and U.J. McMahan.

\section{REFERENCES}

Adler R, Jerdan J, Hewitt AT (1985): Responses of cultured neural retinal cells to substratum-bound laminin and other extracellular matrix molecules. Dev Biol 112:100-114.

Anderson H, Tucker RP (1988): Pioneer neurones use basal lamina as a substratum for outgrowth in the embryonic grasshopper limb. Development 104:601-608.

Avnur Z, Geiger B (1984): Immunocytochemical localization of native chondroitin-sulfate in tissues and cultured cells using specific monoclonal antibody. Cell 38:811-822.

Bodick N, Levinthal C (1980): Growing optic nerve fibers follow ncighbors during embryogenesis. Proc Natl Acad Sci USA 77: $4374-4378$.

Bonhoeffer F, Gierer A (1984): How do retinal axons find their targets on the tectum? Trends Neurosci $7: 378-381$.
Bovolenta P, Mason C (1987): Growth cone morphology varies with position in the developing mouse visual pathway from retina to first targets. J Neurosci 7:1447-1460.

Condic ML, Bentley D (1989): Pioneer neuron pathfinding from normal and ectopic locations in vivo after removal of the basal lamina. Neuron 3:427-439.

Davis GE, Blaker SN, Engvall E, Varon S, Manthorpe M, Gage FH (1987): Human amnion membrane serves as a substratum for growing axons in vitro and in vivo. Science 236:1106-1109.

DeLong GR, Coulombre AJ (1965): Development of the retino-tectal topographic projection in the chick embryo. Exp Neurol 13: $351-363$.

Dodd J, Jessell TM (1988): Axon guidance and the patterning of neuronal projections in vertebrates. Science 242:692-699.

Dow KE, Mirski SEL, Roder JC, Riopelle RJ (1988): Neuronal proteoglycans: Biosynthesis and functional interaction with neurons in vitro. J Neurosci 8:3278-3289.

Dziadek M, Fujiwara S, Paulsson M, Timpl R (1985a): Immunological characterization of basement membrane types of heparan sulfate proteoglycan. EMBO J 4:904-912.

Driadek M, Paulsson M, Timpl R (1985b): Identification and interaction repertoire of large forms of the basement membrane protein nidogen. EMBO J 4:2513-2518.

Easter SE, Bratton B, Scherer SS (1984): Growth-related order of the retinal fiber layer in goldfish. J Neurosci 4:2173-2190.

Fallon JR (1985): Neurite guidance by non-neuronal cells in culture: Preferential outgrowth of peripheral neurites on glial as compared to nonglial cell surlaces. J Neurosci 5:3169-3177.

Goldberg S (1974): Studies on the mechanics of development of the visual pathways in the chick embryo. Dev Biol 36:24-43.

Halfter W (1988): Aberrant optic axons in the retinal pigment epithe lium during chick and quail visual pathway development. J Comp Neurol 268:161-170.

Halfter W, Newgreen DF, Sauter J, Schwary U (1983): Oriented outgrowth from avian embryonic retinae in culture. Dev Biol 95: $56-64$.

Halfter W, Deiss S (1986): Axonal pathfinding in organ-cultured embryonic avian retinae. Dev Biol 114:296-310.

Halfter W, Reckhaus W, Kroger S (1987): Nondirected axonal growth on basal lamina from avian embryonic neural retina. J Neurosci $7: 3712-3722$.

Halfter W, Chiquet-Ehrismann R, Tucker RP (1989): The effect of tenascin and embryonic basal lamina on the behavior and morphology of neural crest cells in vitro. Dev Biol 132:14-25.

Hantaz-Ambroise D, Vigny M, Koenig J (1987): Heparan sulfate proteoglycan and laminin mediate two different types of neurite outgrowth. J Neurosci 7:2293-2304.

Harris WA, Holt CE, Bonhoeffer F (1987): Retinal axons with and without their somata, growing to and arborizing in the tectum of Xenopus embryos: a time-lapse video study of single fibres in vivo. Development 101:123-133.

Hinds JE, Hinds PL (1974): Early ganglionic cell differentiation in the mouse retina: an electron microscopic analysis utilizing serial sections. Dev Biol 37:381-416.

Holley JA (1982): Early development of the circumferential axonal pathway in mouse and chick spinal cord. J Comp Neurol 205: 371--382.

Holt CE (1989): A single-cell analysis of early retinal ganglion cell differentiation in Xenopus: From soma to axon tip. J Neurosci 9:3123-3145.

Kanwar YS, Farquhar MG (1979): Anionic sites in the glomerular basement membrane. In vivo and in vitro localization to the laminae rarae by cationic probes. J Cell Biol 81:137-153. 
Kuffler DP (1986): Thickncss of the basal lamina at the frog neuromuscular junction. J Comp Neurol 250:236-241.

Kuwada JY (1986): Cell recognition by neuronal growth cones in a simple vertebrate embryo. Science 233:740-746.

Letourneau PC, Madsen AM, Palm SL, Furcht LT (1988): Immunoreactivity for laminin in the developing ventral longitudinal pathway of the brain. Dev Biol 125:135-144.

Manthorpe M, Engvall E, Ruoslahti E, Longo FM, Davis GE. Varon S. (1983): Laminin promotes neuritic regeneration from cultured peripheral and central neurons. J Cell Biol 97: $1882-1890$

Matsusaka T (1971): The fine structure of the inner limiting membrane of the cat retina as revealed by ruthenium red staining. J Ultrastruct Res 36:312-317.

Nakamura H, O'Leary DDM (1989): Inaccuracies in initial growth and arborization of chick retinotectal axons followed by course corrections and axon remodeling to develop topographic order. J Neurosei 9:3776-3795.

Nardi NB (1983): Neuronal pathfinding in developing wings of the moth manduca sexta. Dev Biol 95:163-174.

Newgreen DF (1984): Spreading of explants of embryonic chick mesenchymes and epithelia on fibronectin and laminin. Cell Tissue Res 236:265-277.

Newgreen DF, Scheel M, Kastner V (1986): Morphogenesis of sclerotome and neural crest in avian embryos: In vivo and in vitro studies on the role of notochordal extracellular material. Cell Tissue Res 244:299-313.

Nordlander RH, Singer M (1982): Morphology and position of growth cones in the developing Xenopus spinal cord. Dev Brain Res $4: 181-193$.

Patterson PH (1988): On the importance of being inhibited, or saying no to growth cones. Neuron 1:263-267.

Puelles L, Bendala MC (1978): Differentiation of neuroblasts in the chick optic tectum up to eight days of incubation. A golgi study. Neuroscience 3:307-325.

Rager GH (1980): Development of the retinotectal projection in the chicken. Adv Anat Embryol Cell Biol 63:1-92.

Rcynolds ES (1963): The use of lead citrate at high $\mathrm{pH}$ as an electronopaque stain in electron microscopy. J Cell Biol 17:208212.

Roberts A, Taylor ISH (1982): A scanning electron microscope study in the development of a peripheral sensory neurite network. J Embryol Exp Morphol 69:237-250.

Rogers SL, Letourncau PC, Palm SL, McCarthy J, Furcht LT (1983): Neurite extension by peripheral and central nervous system neurons in response to substratum-bound fibronectin and laminin. Dev Biol 98:212-220.

Rösner H, Al-Aqtum M, Henke-Fahle S (1985): Developmental expression of $\mathrm{GD}_{3}$ and polysialogangliosides in embryonic chicken nervous tissue reacting with monoclonal antiganglioside antibodics. Dev Brain Res 18:85-95.

Rösner H, Greis C, Henke-Fahle S (1988): Developmental expression in embryonic rat and chicken brain of a polysialogangliosideantigen reacting with the monoclonal antibody Q 211. Dev Brain Res 42:161-171.

Sanes JR (1989): Extracellular matrix molecules that influence neural development. Annu Rev Neurosci 12:49i-516.

Scherer SS, Easter SE (1984): Degenerative and regenerative changes in the trochlear nerve of goldfish. J Neurocytol 13:519-565.

Schittny JC, Timpl R, Engel J (1988): High resolution immunoelectron microscopic localization of functional domains of laminin, nidogen, and heparan sulfate proteoglycan in cpithelial basement membrane of mouse cornea reveals different topological orientations. J Cell Biol 107:1599-1610.

Silver J, Sidman RL (1980): A mechanism for the guidance and topographical patterning of retinal ganglion cell axons. J Comp Neurol 189:101-111.

Singer M, Nordlander RH, Egar M (1979): Axonal guidance during embryogenesis and regeneration in the spinal cord of the newt: "The blueprint hypothesis" of neuronal pathway patterning. J Comp Neurol 185:1-22.

Thanos S, Bonhoeffer F (1983): Investigations on the development and topographic order of retinotectal axons: Anterograde and retrograde staining of axons and perikarya with Rhodamine in vivo. J Comp Neurol 219:420-430.

Thanos S, Bonhoeffer F (1986): Course corrections of deflected retinal axons on the tectum of the chick embryo. Neurosci Lett $72: 31-36$.

Thanos S, Bonhoeffer F, Rutishauser U (1984): Fiber-fiber interaction and tectal cues influence the development of the chicken retinotectal projection. Proc Natl Acad Sci USA 81:1906-1910.

Timpl R (1982): Antibodies to collagens and procollagens. Methods Enzymol 82:472-498.

Timpl R, Dziadek M (1986): Structure, development, and molecular pathology of bascment membranes. Int Rev Exp Pathol 29: $1-112$.

Vanselow J, Thanos S, Godement $\mathrm{P}$, Henke-Fahle $\mathrm{S}$, Bonhoeffer $\mathrm{F}$ (1989): Spatial arrangement of radial glia and ingrowing retinal axons in the chick optic tectum during development. Dev Brain Res 45:15-27.

Walter J, Kern-Veits B, Huf J, Stolze B, Bonhoeffer F (1987a): Reeognition of position-specific properties of tectal cell mernbranes by retinal axons in vitro. Development 101:685-696.

Walter J, Henke-Fahle S, Bonhoeffer F (1987b): Avoidance of pos terior tectal membranes by temporal retinal axons. Development 101:909-913.

Williams RW, Bastiani J, Lia B, Chalupa LM (1986): Growth cones, dying axons and developmental fluctuations in the fiber population of the cat's optic nerve. J Comp Neurol 246:62-96. 